\title{
Effects of controlled inspiratory muscle training in patients with COPD: a meta-analysis
}

\author{
F. Lötters*, B. van Tol", G. Kwakkel ${ }^{\#}$, R. Gosselink
}

Effects of controlled inspiratory muscle training in patients with COPD: a metaanalysis. F. Lötters, B. van Tol, G. Kwakkel, R. Gosselink. (C) ERS Journals Ltd 2002. ABSTRACT: The purpose of this meta-analysis is to review studies investigating the efficacy of inspiratory muscle training (IMT) in chronic obstructive pulmonary disease (COPD) patients and to find out whether patient characteristics influence the efficacy of IMT.

A systematic literature search was performed using the Medline and Embase databases. On the basis of a methodological framework, a critical review was performed and summary effect-sizes were calculated by applying fixed and random effects models.

Both IMT alone and IMT as adjunct to general exercise reconditioning significantly increased inspiratory muscle strength and endurance. A significant effect was found for dyspnoea at rest and during exercise. Improved functional exercise capacity tended to be an additional effect of IMT alone and as an adjunct to general exercise reconditioning, but this trend did not reach statistical significance. No significant correlations were found for training effects with patient characteristics. However, subgroup analysis in IMT plus exercise training revealed that patients with inspiratory muscle weakness improved significantly more compared to patients without inspiratory muscle weakness.

From this review it is concluded that inspiratory muscle training is an important addition to a pulmonary rehabilitation programme directed at chronic obstructive pulmonary disease patients with inspiratory muscle weakness. The effect on exercise performance is still to be determined.

Eur Respir J 2002; 20: 570-576.
*Dept of Public Health, Faculty of Medicine and Health Sciences, Erasmus University Rotterdam, Rotterdam, and ${ }^{\#}$ Dept of Physical Therapy and Research Institute for Fundamental and Clinical Human Movement Sciences, University Hospital Vrije Uniyersteit, Amsterdam, the Netherlands. Dept of Respiratory Rehabilitation, University Hospitals Leuven, Katholieke Universiteit, Leuven, Belgium.

Correspondence: F. Lötters, Dept of Public Health, Faculty of Medicine and Health Sciences, Erasmus University Rotterdam, PO Box 1738, 3000 DR Rotterdam, the Netherlands.

Fax: 31104089449

E-mail: lotters@mgz.fgg.eur.nl

Keywords: Chronic obstructive pulmonary disease, dyspnoea, inspiratory muscles, meta-analysis, training

Received: April 172001

Accepted after revision: September 1 2001
In their meta-analysis, SMith et al. [1] concluded that inspiratory muscle training (IMT) in patients with chronic obstructive pulmonary disease (COPD) did not reveal significant treatment effects. However, in a subsequent sensitivity analysis, they found a significant difference in inspiratory muscle strength (maximum static inspiratory alveolar pressure $(P \mathrm{I}, \max ))$ and dyspnoea in treatment groups in which training loads were controlled compared to an uncontrolled condition. They postulated that when the training loads are controlled, increment in inspiratory muscle strength and endurance might be translated into a clinically meaningful improvement in functional status.

Over the past 8 yrs, new studies in which training loads were controlled have been performed to reveal the efficacy of IMT. Most of these studies were discussed in two extended reviews on the efficacy of pulmonary rehabilitation $[2,3]$. However, unlike that of Sмiтh et al. [1], these reviews did not employ a meta-analysis of the included studies. Both reviews concluded that despite the adjusted training strategy, the clinical relevance of IMT is still equivocal. In addition, it was suggested that the choice of outcome measures and methodological quality might influence the efficacy of IMT [2, 3].

Besides differences in training strategy and methodological quality, patient characteristics, such as degree of hyperinflation, severity of airway obstruction and respiratory muscle weakness, might also influence the efficacy of IMT.

The purpose of the present study is to provide an update on the efficacy of IMT through a metaanalysis of studies evaluating the efficacy of IMT in patients with COPD. Special attention will be given to patient characteristics that may influence the efficacy of IMT, in order to select the appropriate patients with COPD for the application of IMT.

\section{Methods}

\section{Study identification and selection}

The databases used for selection of the literature were Medline (from 1966 to December 2000), Embase (from 1988 to December 2000), and relevant 
references from peer reviewed articles. The keywords used in the literature search were: 1) respiratory muscles and synonyms; 2) COPD, chronic airflow limitation (CAL) or chronic airflow obstruction (CAO); 3) exercise or training; and 4) human. Literature was screened on title and/or abstract contents. Articles not written in English, Dutch or German were excluded. Studies also had to meet the following criteria. 1) The study must have involved a true experimentation (i.e. randomised controlled trial). 2) Only patients with COPD were studied. 3) Patients in the treatment group received inspiratory muscle training at an intensity of $\geqslant 30 \% P \mathrm{I}$, max $[4,5]$. 4) Pulmonary function tests must have been conducted. 5) Outcomes were described in terms of $P \mathrm{I}, \max$ inspiratory muscle endurance, dyspnoea rating, 6- or 12-min walking distance (6- or 12MWD) and/or heath-related quality of life.

\section{Critical review}

The methodological quality of each of the included studies was evaluated by two independent reviewers (F. Lötters and $B$. van Tol) using a modification of the framework for methodological quality used by SмIтH et al. [1] (table 1). Agreement regarding each criterion was evaluated by weighted Kappa statistic. Disagreements regarding methodological quality were resolved by discussion between the reviewers. When disagreement persisted, a third reviewer (R. Gooselink) made the final decision.

\section{Meta-analysis}

The effect-size of each individual study was calculated by the difference between means of the treatment group and the control group after treatment, divided by the pooled SD of the post-treatment outcome measure of the treatment and control group $[1,6,7]$. The calculated effect-sizes were weighted for sample size and subsequently summarised to obtain a weighted summary effect-size (SES) [6, 7].

The homogeneity test statistic (Q-statistic) of each set of effect-sizes was examined to determine whether studies shared a common effect-size, the variance of which could only be explained by sampling error. If a significant heterogeneity between individual effect-sizes was found, a random effects model was applied [7, 8]. Outcomes of interest included PI,max, inspiratory muscle endurance (expressed in $\mathrm{s}$ or sustained $\% P_{\mathrm{I}}$,max), functional exercise capacity (6MWD or 12MWD), maximal exercise capacity (oxygen consumption-peak, maximal minute ventilation $\left(V^{\prime} \mathrm{E}, \max \right)$ ), dyspnoea rating and heath-related quality of life measures.

In order to control for the effects of possible publication bias on calculated SESs, the Rosenthal's "File Drawer Method" was applied [9]. This method calculates the number of studies needed to achieve a p-value of $>0.05$.

Table 1.-Criteria for methodological quality

Score

Randomisation

Randomisation procedure described

Randomisation procedure not

described (or unable to tell)

Similarity of groups

Age, sex, FEV1, PI,max, walking

distance

Co-intervention

Comparable frequency of visits

Comparable medication changes

Comparable number of intercurrent illnesses

Masking

Patient

Therapist

Researcher

Outcome measures

Validity and/or reliability mentioned or referred to

Validity and/or reliability not mentioned or referred to

Compliance

Training was supervised

Home programme with reporting

diary and periodic control visit

Home programme with either diary

or periodic control visit

Compliance not measured

(or unable to tell)

Exercise regime

Adequate description of intensity, duration and frequency in both exercise and control group

No adequate description of intensity, duration and frequency

Follow-up

90-100\% follow-up

$80-89 \%$ follow-up

$<80 \%$ subjects accounted for

Cannot tell

\section{5 \\ 0}

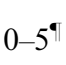

$0-5^{\top}$

$0-5$

5

5

4

FEV1: forced expiratory volume in one second; PI,max: maximum static inspiratory alveolar pressure. \#: total score $=40$ points; 5 for 3 out of 3,4 for 2 out of 3,3 for 1 out of 3 and 0 for 0 out of 3 .

\section{Sensitivity analysis}

The influence of the methodological quality of individual studies on SES was analysed through use of a weighting factor for each study. This weighting factor was calculated by dividing the quality score of each study by the maximum feasible score of 40 points. Subgroup analysis was performed for studies adding IMT to general exercise reconditioning and to trace whether the specificity of the training device (threshold loading or flow-resistive loading) influences the efficacy of IMT.

To determine possible prognostic characteristics of the effectiveness of IMT, Spearman rank correlation coefficients were calculated for baseline values (forced expiratory volume in one second (FEV1), forced residual capacity (FRC), $P \mathrm{I}$,max and carbon dioxide tension in arterial blood $\left.\left(\mathrm{Pa}_{\mathrm{a}}, \mathrm{CO}_{2}\right)\right)$ and 
improvements in inspiratory muscle strength and endurance in the treatment group.

\section{Results}

\section{Critical review}

Fifty-seven studies were identified by the literature search. After screening these studies through use of the inclusion criteria, 15 studies were included in the present meta-analysis [10-24]. From these studies, five $[10,12-14,17]$ had also been included in the metaanalysis of SмITH et al. [1]. From the initial 57 studies, 20 did not fulfil the criteria of COPD, 18 were not randomised controlled trails, 30 did not use a training intensity of $\geqslant 30 \% P \mathrm{I}$,max, six did not employ relevant pulmonary function tests, and in 12 studies no relevant outcome measures were used with regard to this meta-analysis.

The weighted Kappa on inter-observer agreement for the validity criteria varied from $0.59-1$ (median 0.79 ). The methodological quality score varied from 12-31 (median 24) of the maximal feasible score of 40 points. The main methodological shortcomings were lack of an adequate description of randomisation procedure, no validity and reliability data of the used outcome measures mentioned, and absence of (double) blinding procedures.

The overall treatment group contained 200 subjects and the control group 183. The main patient characteristics of the overall treatment group were: age $63 \pm 7 \quad(\mathrm{n}=200)$, height $170 \pm 8 \mathrm{~cm} \quad(\mathrm{n}=73)$, weight $70 \pm 13 \mathrm{~kg}(\mathrm{n}=97)$, body mass index $25 \pm 4(\mathrm{n}=65), \mathrm{FEV} 1$ $43 \pm 15 \% \quad(\mathrm{n}=171), \quad$ FRC $148 \pm 42 \% \quad(\mathrm{n}=148), \quad P \mathrm{I}, \max$ $71 \pm 21 \% \quad(\mathrm{n}=200)$, and $P_{\mathrm{a}}, \mathrm{CO}_{2} \quad 41 \pm 6 \mathrm{mmHg} \quad(\mathrm{n}=148)$. Pulmonary function variables were expressed in $\%$ predicted using the normative data of QUANJER et al.
[25]. PI,max was normalised using normative data from Rochester and Arora [26]. PI,max was assessed with maximal inspiratory mouth pressures from residual volume $(\%)[11,12,14,15,17,18,24]$ or FRC (\%) [10, 19-22]. In one study [23], the sniff test was used to determine transdiaphragmatic pressure as measurement of inspiratory muscle strength.

\section{Meta-analysis}

Table 2 shows the results of the overall analysis. Significant SESs were found for inspiratory muscle strength, endurance and dyspnoea. Functional exercise capacity tended to be an additional effect of IMT, but this did not reach statistical significance $(\mathrm{p}=0.11)$.

Meta-analysis was not performed on health-related quality of life, since different outcome measures were used [12, 16-18], which hampers interpretation of the findings. DekhUIJZEN et al. [12] used the SCL-90 and activities of daily living (ADL) list and found a significant improvement in both training and control groups, whereas no significant differences were observed between the groups. LARSON et al. [18] found similar results using the chronic respiratory disease questionnaire (CRQ)-dyspnoea scale and the CRQ fatigue scale. In the other two studies, which used the Sickness Impact Profile, no significant effect on heath-related quality of life was found $[16,17]$.

None of the baseline values of pulmonary function, inspiratory muscle strength and $\mathrm{Pa}_{\mathrm{a}} \mathrm{CO}_{2}$ were significantly related to improvements in inspiratory muscle strength or inspiratory muscle endurance.

In the overall analysis, the homogeneity test statistic (Q-statistic) was not significant for all outcomes (table 2). This implies that effect-sizes were homogeneous between studies, when compared with the variance within studies involved. After weighting for

Table 2. - Overall results of the meta-analysis using the fixed effect model

\begin{tabular}{|c|c|c|c|c|c|c|c|}
\hline Outcome measure & $\begin{array}{l}\text { Studies } \\
\mathrm{n}\end{array}$ & $\begin{array}{c}\text { Weighted } \\
\text { averaged effect-size }\end{array}$ & $\begin{array}{l}\text { Natural } \\
\text { units }\end{array}$ & $\begin{array}{l}95 \% \\
\mathrm{CI}\end{array}$ & Z-statistic & $\begin{array}{l}\text { Homogeneity } \\
\text { Q-statistic }\end{array}$ & $\begin{array}{l}\text { Studies } \\
\text { needed }^{\#} \mathrm{n}\end{array}$ \\
\hline $\begin{array}{l}\text { Inspiratory muscle } \\
\text { strength } P \mathrm{I}, \max \end{array}$ & 15 & 0.56 & $10.5 \mathrm{cmH}_{2} \mathrm{O}$ & $0.35-0.77$ & $5.27 *$ & 16.83 & $\geqslant 77$ \\
\hline $\begin{array}{l}\text { Inspiratory muscle } \\
\text { endurance MVV }\end{array}$ & 4 & 0.21 & $2.8 \mathrm{~L} \cdot \min ^{-1}$ & $-0.29-0.70$ & 0.82 & 1.38 & \\
\hline $\begin{array}{l}\text { Inspiratory muscle } \\
\text { endurance s }\end{array}$ & 7 & 0.41 & $154.2 \mathrm{~s}$ & $0.14-0.68$ & $2.94 * *$ & 6.67 & $\geqslant 14$ \\
\hline $\begin{array}{l}\text { Inspiratory muscle } \\
\text { endurance } \mathrm{cmH}_{2} \mathrm{O}\end{array}$ & 4 & 1.16 & $10.3 \mathrm{cmH}_{2} \mathrm{O}$ & $0.67-0.15$ & $4.67 *$ & 5.39 & $\geqslant 10$ \\
\hline $\begin{array}{l}\text { Functional exercise } \\
\text { capacity 6- or } \\
\text { 12MWD }\end{array}$ & 8 & 0.22 & $48.1 \mathrm{~m}$ & $-0.05-0.48$ & 1.58 & 2.58 & \\
\hline $\begin{array}{l}\text { Laboratory exercise } \\
\text { capacity } V^{\prime} \mathrm{O}_{2}, \max \end{array}$ & 5 & 0.04 & $-0.04 \mathrm{~L} \cdot \mathrm{min}^{-1}$ & $-0.36-0.29$ & -0.24 & 2.50 & \\
\hline $\begin{array}{l}\text { Laboratory Exercise } \\
\text { capacity } V^{\prime} \mathrm{E}, \max \end{array}$ & 5 & 0.03 & $-1.5 \mathrm{~L} \cdot \mathrm{min}^{-1}$ & $-0.03-0.35$ & 0.16 & 5.49 & \\
\hline $\begin{array}{l}\text { Dyspnea-Borg } \\
\text { exercise-related }\end{array}$ & 5 & -0.55 & -1.5 & $-0.90-0.19$ & $-3.10 * *$ & 3.69 & $\geqslant 10$ \\
\hline Dyspnoea-TDI rest & 2 & 2.3 & 2.7 & $1.44-3.15$ & $5.28 * *$ & 4.14 & $\geqslant 14$ \\
\hline
\end{tabular}

CI: confidence interval; PI,max: maximum static inspiratory alveolar pressure; MVV: maximal voluntary ventilation; 6- or 12MWD: 6- or 12-min walking distance; $V^{\prime} \mathrm{O}_{2}$,max: maximal oxygen consumption; $V^{\prime} \mathrm{E}$,max: maximal minute ventilation; TDI: transitional dyspnoea index. ${ }^{\#}$ : studies needed for $\mathrm{p}>0.05 ; * *: \mathrm{p}<0.01 ; * * *: \mathrm{p}<0.001$. 
differences in methodological quality, sensitivity analysis showed almost identical SESs and concomitant confidence intervals for all outcomes.

In the 15 studies included, two types of inspiratory muscle loading were applied: targeted resistive training $[10,12,14,15,20]$ and training with a threshold loading device $[11,13,16-19,21-24]$. Subgroup analysis revealed that there were no differences in the outcome of inspiratory muscle strength (Chisquared $=0.009, \quad \mathrm{p}=0.93$ ) and inspiratory muscle endurance (Chi-squared $=0.36, p=0.55$ ) regarding the different types of training.

Inspiratory muscle training as an adjunct to general exercise reconditioning

The subgroup analysis of studies adding IMT to general exercise reconditioning revealed significantly weighted SESs of inspiratory muscle strength and endurance (table 3). No additional effect on functional exercise capacity was observed $(\mathrm{p}=0.34)$. Due to the significantly heterogeneous outcome for inspiratory muscle strength (Chi-squared $=13.28, \mathrm{p}<0.05$ ), a subgroup analysis was conducted. The six studies were divided into studies with inspiratory muscle weakness (indicated by a mean baseline $P \mathrm{I}$,max $\leqslant 60 \mathrm{cmH}_{2} \mathrm{O}$ [27]) and one without inspiratory muscle weakness. In this analysis, both subgroups showed homogeneity. The two groups differed significantly in improvement in inspiratory muscle strength (Chi-squared $=8.81$, $\mathrm{p}<0.01)$. Inspiratory muscle strength improved significantly in the group with inspiratory muscle weakness $\left(16 \mathrm{cmH}_{2} \mathrm{O}, \mathrm{z}=4.08, \mathrm{p}<0.001\right)$, but not in the group without inspiratory muscle weakness $\left(-3 \mathrm{cmH}_{2} \mathrm{O}, \mathrm{z}=-0.61, \mathrm{p}=0.54\right)$ (fig. $\left.1 \mathrm{a}\right)$.

Because of the initial heterogeneity, the same analysis was conducted using the random effect model. There was an improvement in PI,max ( $\mathrm{SES}=0.45$, confidence interval=-0.09-0.99) in this analysis, but this did not reach statistical significance because of the wide variance $(\mathrm{z}=1.63, \mathrm{p}=0.10)$. However, the subgroups still differed significantly (Chi-squared $=5.75, \mathrm{p}<0.05)$ (table 4).
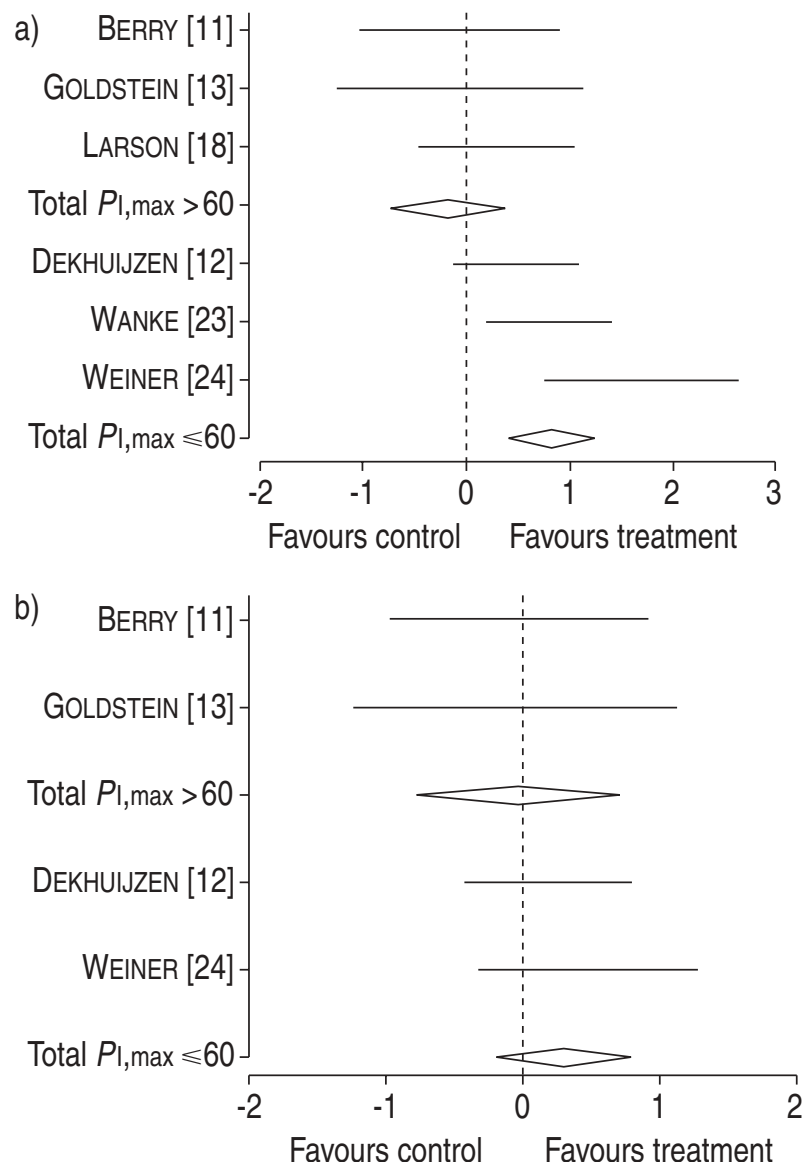

Fig. 1.-Weighted summary effect-sizes of a) inspiratory muscle strength and b) functional exercise capacity (SD units) for the studies with general exercise reconditioning plus inspiratory muscle training. Subgroups were divided on the basis of their baseline maximum static inspiratory alveolar pressue $\left(P_{\mathrm{I}, \max }\right)$ (>60 $\mathrm{cmH}_{2} \mathrm{O}$ : without inspiratory muscle weakness; $\leqslant 60 \mathrm{cmH}_{2} \mathrm{O}$ with inspiratory muscle weakness). The horizontal lines indicate the $95 \%$ confidence intervals of the outcomes. The diamonds indicate the weighted summary effect-sizes of the groups.

The mean weighted effect-size of functional exercise capacity for the group with inspiratory muscle weakness was $0.33 \quad(\mathrm{z}=1.17, \mathrm{p}=0.24)$ and -0.02

Table 3. - Subgroup analysis of general exercise reconditioning plus inspiratory muscle training versus general exercise reconditioning alone using the fixed-effect model

\begin{tabular}{lcccccc}
\hline Outcome measure & $\begin{array}{c}\text { Studies } \\
\mathrm{n}\end{array}$ & $\begin{array}{c}\text { Weighted averaged } \\
\text { effect-size }\end{array}$ & $\begin{array}{c}\text { Natural } \\
\text { units }\end{array}$ & $\begin{array}{c}95 \% \\
\mathrm{CI}\end{array}$ & $\begin{array}{c}\text { Z-statistic } \\
\text { Homogeneity } \\
\text { Q-statistic }\end{array}$ \\
\hline $\begin{array}{l}\text { Inspiratory muscle } \\
\text { strength PI,max }\end{array}$ & 6 & 0.47 & $6.7 \mathrm{cmH}_{2} \mathrm{O}$ & $0.15-0.79$ & $2.88^{* *}$ & $13.28^{*}$ \\
$\begin{array}{l}\text { Inspiratory muscle } \\
\text { endurance MVV }\end{array}$ & 2 & -0.03 & $-0.95 \mathrm{~L} \cdot \mathrm{min}^{-1}$ & $-0.77-0.72$ & -0.07 & 0.14 \\
$\begin{array}{l}\text { Inspiratory muscle } \\
\text { endurance in s }\end{array}$ & 3 & 0.55 & $164.4 \mathrm{~s}$ & $0.14-0.97$ & $2.61^{* *}$ & 0.09 \\
$\begin{array}{l}\text { Functional exercise } \\
\text { capacity 6- or 12MWD }\end{array}$ & 4 & 0.20 & $54 \mathrm{~m}$ & $-0.21-0.61$ & 0.95 & 0.79 \\
$\begin{array}{l}\text { Laboratory exercise } \\
\text { capacity } V^{\prime} \mathrm{O}_{2} \text {,max }\end{array}$ & 3 & -0.17 & $-0.01 \mathrm{~L} \cdot \mathrm{min}^{-1}$ & $-0.69-0.35$ & -0.63 & 0.16 \\
$\begin{array}{l}\text { Laboratory exercise } \\
\text { capacity } V^{\prime} \mathrm{E} \text {,max }\end{array}$ & 3 & -0.10 & $1.2 \mathrm{~L} \cdot \mathrm{min}^{-1}$ & $-0.61-0.42$ & -0.38 & 0.01 \\
\hline
\end{tabular}

CI: confidence interval; $P$ I,max: maximum static inspiratory alveolar pressure; MVV: maximal voluntary ventilation; 6- or 12MWD: 6- or 12-min walking distance; $V^{\prime} \mathrm{O}_{2}$, max: maximal oxygen consumption; $V^{\prime} \mathrm{E}$, max: maximal minute ventilation. ${ }^{*}: \mathrm{p}<0.05 ; * *$ : $<<0.01$. 
$(\mathrm{z}=-0.06, \mathrm{p}=0.95)$ for the group without inspiratory muscle weakness (fig. 1b). This difference, however, was not statistically significant, probably due to the large variability in data.

\section{Discussion}

From the present meta-analysis it can be concluded that IMT alone significantly improves inspiratory muscle strength and endurance, whereas the sensation of dyspnoea significantly decreases in patients with COPD. No significant additional effects of IMT on exercise performance were found. Patient characteristics, such as hyperinflation and degree of severity, and the training device used did not have any effect on the efficacy of IMT. A subgroup analysis of IMT as an adjunct to general exercise reconditioning revealed that inspiratory muscle weakness appeared to play an important role in the efficacy of IMT.

\section{Potential errors in meta-analysis}

Despite some shortcomings in study design, the SESs of all outcomes did not change when methodological quality was used as a weighting factor. A potential problem of conducting a meta-analysis might be the pooling of data from trials with different patient characteristics. However, in the overall analysis, the outcomes were homogeneous with respect to patient characteristics, as indicated by the homogeneity test statistic (Q), justifying the application of a fixed effects model. However, in the subgroup analysis of IMT as an adjunct to general exercise reconditioning, the outcome of inspiratory muscle strength appeared to be significantly heterogeneous, indicating that the studies did not have a common population effect-size regarding the outcome for inspiratory muscle strength. Additional analysis revealed a significant difference in outcome for inspiratory muscle strength in studies that included patients with inspiratory muscle weakness, as indicated by a mean baseline $P \mathrm{I}$,max of $\leqslant 60 \mathrm{cmH}_{2} \mathrm{O}[12,23,24]$, compared to those that included patients with no inspiratory muscle weakness [11, 13, 18] (fig. 1a).

Further analysis of these subgroups indicates that weakness of the inspiratory muscles might be an important prognostic factor of the efficacy of IMT. This finding further confirms that patient selection plays a key role in the efficacy of IMT. Additional analysis revealed that $\sim 25$ unpublished studies (range
10-77) with an average effect of zero are needed to reverse the findings of the present study (table 2).

\section{Efficacy of inspiratory muscle training alone}

The findings of the present meta-analysis are in contrast with the findings of SмIтн et al. [1]. In their meta-analysis, no significant effects of inspiratory muscle strength, endurance and dyspnoea were observed in the overall analysis. However, in their meta-analysis only five out of 17 studies controlled for training load, whereas in the present meta-analysis controlling the training load was a feature in all studies involved.

The result of an increasing $P \mathrm{I}$,max and a concomitant decrease in dyspnoea sensation corresponds with the observed inverse relationship between PI,max and dyspnoea [28-30]. This conclusion supports the suggestion in the joint American College of Chest Physicians and American Association of Cardiovascular and Pulmonary Rehabilitation evidence-based guidelines that IMT might be considered in patients with decreased inspiratory muscle strength and breathlessness [2].

No correlation was found between patient characteristics and improvements in inspiratory muscle strength and endurance when using Spearman rank correlation coefficients. This finding is probably due to the low number of studies $(n \leqslant 15)$ in which the Spearmean rank coefficients were calculated. Furthermore, the Spearman rank coefficients could only be calculated by using the means of the variables of whole studies and not individual patient data, which may have masked a possible association between effects and patient characteristics.

There is no evidence to support resistive or threshold loading as the training method of choice. Resistive breathing has the disadvantage that the inspiratory pressure is flow dependent [10]. Threshold loading has the advantage of being independent of inspiratory flow rate [31]. However, it requires a build up of negative pressure before flow occurs, and hence, is inertive in nature. BELMAN et al. [32] showed that similar work loads were obtained during resistive loading and threshold loading. Threshold loading enhances velocity of inspiratory muscle contraction [22]. This is a favourable alteration of the breathing pattern as it shortens inspiratory time and increases time for exhalation and relaxation. Whether resistive loading or this inertive

Table 4. - Subgroup analysis of general exercise reconditioning plus inspiratory muscle training versus general exercise reconditioning alone, for the outcome inspiratory muscle strength maximum static inspiratory alveolar pressure $\left(P_{1, \text { max }}\right)$ using the random-effect model

\begin{tabular}{lcccrcc}
\hline $\begin{array}{l}\text { Baseline values } \\
\text { PI,max }\end{array}$ & $\begin{array}{c}\text { Studies } \\
\mathrm{n}\end{array}$ & $\begin{array}{c}\text { Weighted averaged } \\
\text { effect-size }\end{array}$ & Natural units & $95 \% \mathrm{CI}$ & Z-statistic & Q-between \\
\hline Total group & 6 & 0.45 & $6.7 \mathrm{cmH}_{2} \mathrm{O}$ & $-0.09-0.99$ & 1.63 & \\
Group 1 & 3 & 0.93 & $16 \mathrm{cmH}_{2} \mathrm{O}$ & $0.20-1.66$ & $2.51^{* *}$ & $5.75^{*}$ \\
Group 2 & 3 & -0.14 & $-3 \mathrm{cmH}_{2} \mathrm{O}$ & $-0.95-0.67$ & -0.35 & \\
\hline
\end{tabular}

CI: confidence intervals. Group 1: $P \mathrm{I}, \max \leqslant 60 \mathrm{cmH}_{2} \mathrm{O}$; Group 2: $P \mathrm{I}, \max >60 \mathrm{cmH}_{2} \mathrm{O}$. *: $\mathrm{p}<0.05 ; * *: \mathrm{p}<0.01$. 
loading produces different training effects, remains to be studied.

\section{Efficacy of inspiratory muscle training as an adjunct to general exercise reconditioning}

From the present meta-analysis, IMT plus general exercise reconditioning appeared to have strong significant training effects on inspiratory muscle strength and endurance, especially in patients with inspiratory muscle weakness.

Only two studies from the subgroup analysis measured exercise-related dyspnoea [11, 18]. Neither study found a significant decrease in dyspnoea after IMT, which was probably due to the high baseline $P I, \max (79 \%$ [11] and 85-110\% [18]), suggesting that inspiratory muscle performance was probably not the primary cause of dyspnoea in these patients.

Improvement in exercise performance in patients with muscle weakness tended to be higher, but failed to reach statistical significance. The small number of studies involved in this subgroup analysis might have affected this. However, the data from this meta-analysis give some indication that IMT as an adjunct to general exercise reconditioning has a beneficial effect on functional exercise capacity in patients with inspiratory muscle weakness.

\section{Functional exercise capacity}

Improved functional exercise capacity tended to be an additional effect of IMT (alone and as an adjunct to general exercise reconditioning), but this trend did not reach statistical significance. This might be due to the fact that ventilatory limitation during exercise, indicated by a rising $P \mathrm{a}, \mathrm{CO}_{2}$ during exercise [33] and/or an increase of the $V^{\prime}$ E/maximal voluntary ventilation (MVV) ratio $>70 \%$ during exercise [34], was used as a selection criterion in only three of the 15 studies included [12, 18, 19]. These three studies all found a significant increase in functional exercise capacity after IMT as an adjunct to general exercise reconditioning. The findings in the present metaanalysis were supported by those in a recent study by SCHERER et al. [35], in which a strong significant increase in functional exercise capacity after IMT in a group of COPD patients with ventilatory limitation $\left(V^{\prime} \mathrm{E} / \mathrm{MVV}=85 \%\right)$ was found in favour of the treatment group. However, it must be stated that the training used in this study (normocapnic hyperpneu) differed from the training used in the studies included in the current meta-analysis. A study by SonNe and DAvis [36] also showed that exercise capacity was significantly increased after IMT in patients with ventilatory limitation $\left(V^{\prime} \mathrm{E} / \mathrm{MVV}>80 \%\right)$ [36]. Accordingly, it is possible that IMT in the other studies was applied to patients in whom inspiratory muscle performance was not the limiting factor of exercise capacity. In the study by BERRY et al. [11], no significant effect of IMT on exercise capacity was found. This was probably due to the fact that the treatment group was not ventilatorily limited
$\left(V^{\prime} \mathrm{E} / \mathrm{MVV}=51 \%\right)$ and had no inspiratory muscle weakness (baseline PI,max $79 \%$ pred). In the study by LARSON et al. [18], a ventilatory limitation was found in the treatment group, but the baseline $P \mathrm{I}$,max was $85-110 \%$ pred, indicating that inspiratory muscle weakness was not the primary cause of the ventilatory limitation during exercise.

The small effect of IMT on functional exercise capacity might also be explained by other physiological factors, such as peripheral muscle weakness [37], or limitations in blood flow directed to the peripheral muscles and oxygen extraction during general exercise reconditioning [38]. However, neither of the included studies addressed this problem. For a better understanding of the limitation that affects functional exercise capacity, these factors have to be considered in future research.

\section{Conclusions and practical implications of the findings}

IMT significantly increased inspiratory muscle strength and inspiratory muscle endurance. In addition, a clinically significant decrease in dyspnoea sensation at rest and during exercise was observed after IMT.

Improved functional exercise capacity tended to be an additional effect of IMT alone and of IMT as an adjunct to general exercise reconditioning, but this trend did not reach statistical significance. It was therefore shown that inspiratory muscle weakness $\left(P \mathrm{I}, \max \leqslant 60 \mathrm{cmH}_{2} \mathrm{O}\right)$ plays a key role in the efficacy of IMT. The role of ventilatory limitation on the efficacy of IMT is still to be determined.

From the present meta-analysis it can be stated that inspiratory muscle training is a meaningful addition to pulmonary rehabilitation programmes directed at chronic obstructive pulmonary disease patients with inspiratory muscle weakness. Future studies evaluating the efficacy of inspiratory muscle training should select patients using these criterion.

\footnotetext{
Acknowledgements. The authors would like to thank M.J. Berry for providing pre- and post-training data, so that it could be included in the present meta-analysis.
}

\section{References}

1. Smith K, Cook D, Guyatt GH, Madhavan J, Oxman AD. Respiratory muscle training in chronic airflow limitation: a meta-analysis. Am Rev Respir Dis 1992; 145: 533-539.

2. Ries A, Kaplan RM, Limberg TM, Prewitt LM. Pulmonary rehabilitation: joint ACCP/AACVPR evidence-based guidelines. ACCP/AACVPR Pulmonary Rehabilitation Guidelines Panel. American College of Chest Physicians. American Association of Cardiovascular and Pulmonary Rehabilitation. Chest 1997; 112: 1363-1396.

3. Lacasse Y, Guyatt GH, Goldstein RS. The components of a respiratory rehabilitation program: a systematic overview. Chest 1997; 111: 1077-1088. 
4. Goldstein RS. Pulmonary rehabilitation in chronic respiratory insufficiency. 3 . Ventilatory muscle training. Thorax 1993; 48: 1025-1033.

5. Grassino A. Inspiratory muscle training in COPD patients. Eur Respir J 1989; 2: Suppl. 7, 581s-586s.

6. Rosenthal R. Parametric measures of effect-size. In: Cooper H, Hedges LV, eds. The handbook of research synthesis. New York, Russell Sage Foundation, 1994; pp. 231-244.

7. Shadish WR, Haddock CK. Combining estimates of effect-size. In: Cooper $\mathrm{H}$, Hedges LV, eds. The handbook of research synthesis. New York, Russell Sage Foundation, 1994; pp. 261-281.

8. Hedges LV. Fixed effect models. In: Cooper $\mathrm{H}$, Hedges LV, eds. The handbook of research synthesis. New York, Russell Sage Foundation, 1994; pp. 285299.

9. Begg CB. Publication bias. In: Cooper H, Hedges LV, eds. The handbook of research synthesis. New York, Russell Sage Foundation, 1994: pp. 399-409.

10. Belman MJ, Shadmehr R. Targeted resistive ventilatory muscle training in chronic obstructive pulmonary disease. J Appl Physiol 1988; 65: 2726-2735.

11. Berry MJ, Adair NE, Sevensky KS, Quinby A, Lever HM. Inspiratory muscle training and whole-body reconditioning in chronic obstructive pulmonary disease. Am J Respir Crit Care Med 1996; 153: 18121816.

12. Dekhuijzen PN, Folgering HT, van Herwaarden CL. Target-flow inspiratory muscle training during pulmonary rehabilitation in patients with COPD. Chest 1991; 99: 128-133.

13. Goldstein R, De Rosie J, Long S, Dolmage T, Avendano MA. Applicability of a threshold loading device for inspiratory muscle testing and training in patients with COPD. Chest 1989; 96: 564-571.

14. Harver A, Mahler DA, Daubenspeck JA. Targeted inspiratory muscle training improves respiratory muscle function and reduces dyspnea in patients with chronic obstructive pulmonary disease. Ann Intern Med 1989; 111: 117-124.

15. Heijdra YF, Dekhuijzen PN, van Herwaarden CL, Folgering HT. Nocturnal saturation improves by target-flow inspiratory muscle training in patients with COPD. Am J Respir Crit Care Med 1996; 153 : 260-265.

16. Kim MJ, Larson JL, Covey MK, Vitalo CA, Alex CG, Patel M. Inspiratory muscle training in patients with chronic obstructive pulmonary disease. Nurs Res 1993; 42: 356-362.

17. Larson JL, Kim MJ, Sharp JT, Larson DA. Inspiratory muscle training with a pressure threshold breathing device in patients with chronic obstructive pulmonary disease. Am Rev Respir Dis 1988; 138: 689-696.

18. Larson JL, Covey MK, Wirtz SE, et al. Cycle ergometer and inspiratory muscle training in chronic obstructive pulmonary disease. Am J Respir Crit Care Med 1999; 160: 500-507.

19. Lisboa C, Villafranca C, Leiva A, Cruz E, Pertuze J, Borzone $\mathrm{G}$. Inspiratory muscle training in chronic airflow limitation: effect on exercise performance. Eur Respir J 1997; 10: 537-542.

20. Patessio A, Rampulla C, Fracchia C, et al. Relationship between the perception of breathlessness and inspiratory resistive loading: report on a clinical trial. Eur Respir J Suppl 1989; 2: Suppl. 7, 587s-591s.

21. Preusser BA, Winningham ML, Clanton TL. High- $v s$ low-intensity inspiratory muscle interval training in patients with COPD. Chest 1994; 106: 110-117.

22. Villafranca C, Borzone G, Leiva A, Lisboa C. Effect of inspiratory muscle training with an intermediate load on inspiratory power output in COPD. Eur Respir J 1998; 11: 28-33.

23. Wanke T, Formanek D, Lahrmann H, et al. Effects of combined inspiratory muscle and cycle ergometer training on exercise performance in patients with COPD. Eur Respir J 1994; 7: 2205-2211.

24. Weiner P, Azgad Y, Ganam R. Inspiratory muscle training combined with general exercise reconditioning in patients with COPD. Chest 1992; 102: 13511356.

25. Quanjer $\mathrm{PhH}$, Tammeling GJ, Cotes JE, et al. Symbols, abbreviations and units. Working Party Standardization of Lung Function Tests, European Community for Steel and Coal. Eur Respir 1993; 6: Suppl. 16, 85-100.

26. Rochester DF, Arora NS. Respiratory muscle failure. Med Clin North Am 1983; 67: 573-597.

27. Tobin MJ. Respiratory muscles in disease. Clin Chest Med 1988; 9: 263-286.

28. American Thoracic Society. Dyspnea. Mechanisms, assessment, and management: a consensus statement. Am J Respir Crit Care Med 1999; 159: 321-340.

29. Killian KJ, Jones NL. The use of exercise testing and other methods in the investigation of dyspnea. Clin Chest Med 1984; 5: 99-108.

30. O'Donnell DE. Breathlessness in patients with chronic airflow limitation. Mechanisms and management. Chest 1994; 106: 904-912.

31. Gosselink R, Wagenaar RC, Decramer M. Reliability of a commercially available threshold loading device in healthy subjects and in patients with chronic obstructive pulmonary disease. Thorax 1996; 51: 601-605.

32. Belman MJ, Botnick WC, Nathan SD, Chon KH. Ventilatory load characteristics during ventilatory muscle training. Am J Respir Crit Care Med 1994; 149: 925-929.

33. Begin $\mathrm{P}$, Grassino A. Inspiratory muscle dysfunction and chronic hypercapnia in chronic obstructive pulmonary disease. Am Rev Respir Dis 1991; 143: 905-912.

34. Fitting JW. Respiratory muscle fatigue limiting physical exercise? Eur Respir J 1991; 4: 103-108.

35. Scherer TA, Spengler CM, Owassapian D, Imhof E, Boutellier U. Respiratory muscle endurance training in chronic obstructive pulmonary disease. Impact on exercise capacity, dyspnea, and quality of life. $A m$ J Respir Crit Care Med 2000; 162: 1709-1714.

36. Sonne LJ, Davis JA. Increased exercise performance in patients with severe COPD following inspiratory resistive training. Chest 1982; 81: 436-439.

37. Gosselink R, Troosters T, Decramer M. Peripheral muscle weakness contributes to exercise limitation in COPD. Am J Respir Crit Care Med 1996; 153: 976980.

38. Simon M, LeBlanc P, Jobin J, Desmeules M, Sullivan MJ, Maltais F. Limitation of lower limb $\mathrm{VO}(2)$ during cycling exercise in COPD patients. J Appl Physiol 2001; 90: 1013-1019. 